\title{
Case Report of a Pituitary Metastasis from Lung Adenocarcinoma Masquerading as Pituitary Adenoma
}

\author{
Radhamani Rajakumar, Ijaz Hallaj Rahmatullah, Anilah Abdul Rahim \\ Hospital Raja Permaisuri Bainun Ipoh, Malaysia
}

\begin{abstract}
Metastasis to the pituitary gland is an unusual situation in clinical practice and is typically observed in those with underlying malignancy with breast and lung being the commonest primary site. However, we report a case of an apparently well 49-year-old female with metastatic lung adenocarcinoma who presented with visual disturbance and diabetes insipidus related to pituitary metastasis as an initial presentation.
\end{abstract}

Key words: pituitary metastasis, diabetes insipidus, lung adenocarcinoma

\section{INTRODUCTION}

Cancers metastatic to the pituitary gland are uncommon and account for only $1.8 \%$ of all metastases and $1 \%$ of all pituitary cancers. ${ }^{1}$ The breast and lung are the most frequent primary sites. Although the majority of patients are asymptomatic and often diagnosed at autopsy, two of the largest reported series noted that symptoms from the pituitary metastasis were the initial manifestation of metastatic disease in over half of the patients., ${ }^{2,3}$ Diabetes insipidus was by far the most frequent symptom, occurring in $45 \%$ of patients, followed by optic nerve dysfunction $(28 \%)$; anterior pituitary dysfunction $(24 \%)$; palsies of cranial nerves III, IV, or VI (22\%); and headache (16\%). ${ }^{4}$

\section{CASE}

A 49-year-old female with no significant medical history presented with one-month history of progressive peripheral vision loss and headache. She had also experienced polydipsia with polyuria and further history revealed that she was amenorrhoeic for one year. Otherwise, she has no respiratory or constitutional symptoms. Physical examination was unremarkable except that visual field examination confirmed bitemporal hemianopia (Figure 1). A subsequent cranial magnetic resonance imaging (MRI) scan displayed a lobulated heterogeneous enhancing mass approximately $1.7 \times 1.9 \times 2.0 \mathrm{~cm}$ arising from the sella turcica with suprasellar extension and
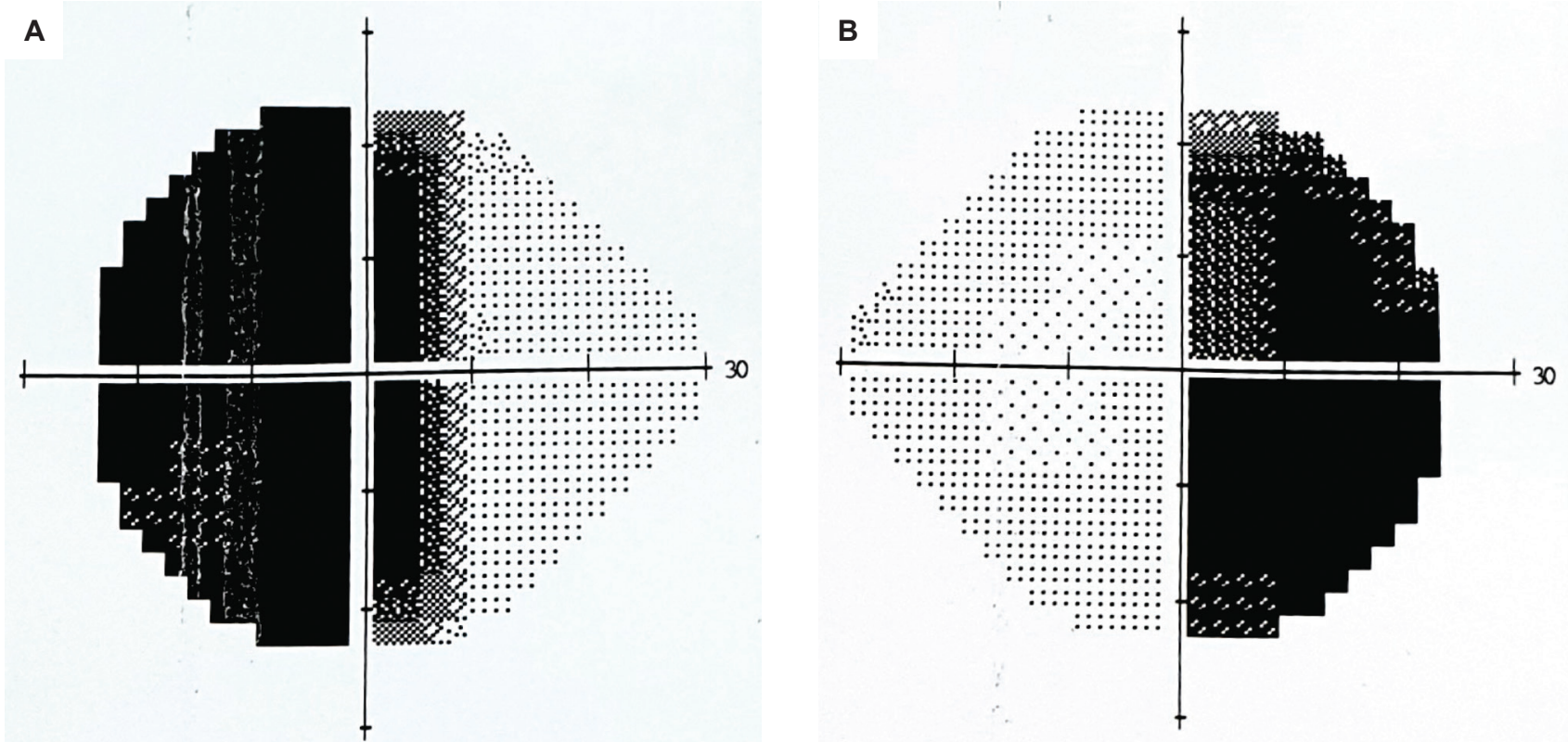

Figure 1. Humphrey visual field test results for patient's left (A) and right (B) eyes, confirming a dense bitemporal visual loss.

\footnotetext{
ISSN 0857-1074 (Print) I eISSN 2308-118x (Online) Printed in the Philippines

Copyright $(0) 2020$ by Rajakumar et al.

Received: February 23, 2020. Accepted: April 14, 2020

Published online first: April 28, 2020.

https://doi.org/10.15605/jafes.035.01.24
}

Corresponding author: Radhamani Rajakumar, MD Endocrine Fellow, Hospital Raja Permaisuri Bainun Jalan Hospital, 30990, Ipoh, Perak, Malaysia Tel. No.: 05-2085000

E-mail:mini212@yahoo.com

ORCiD: https://orcid.org/0000-0003-3370-1949 

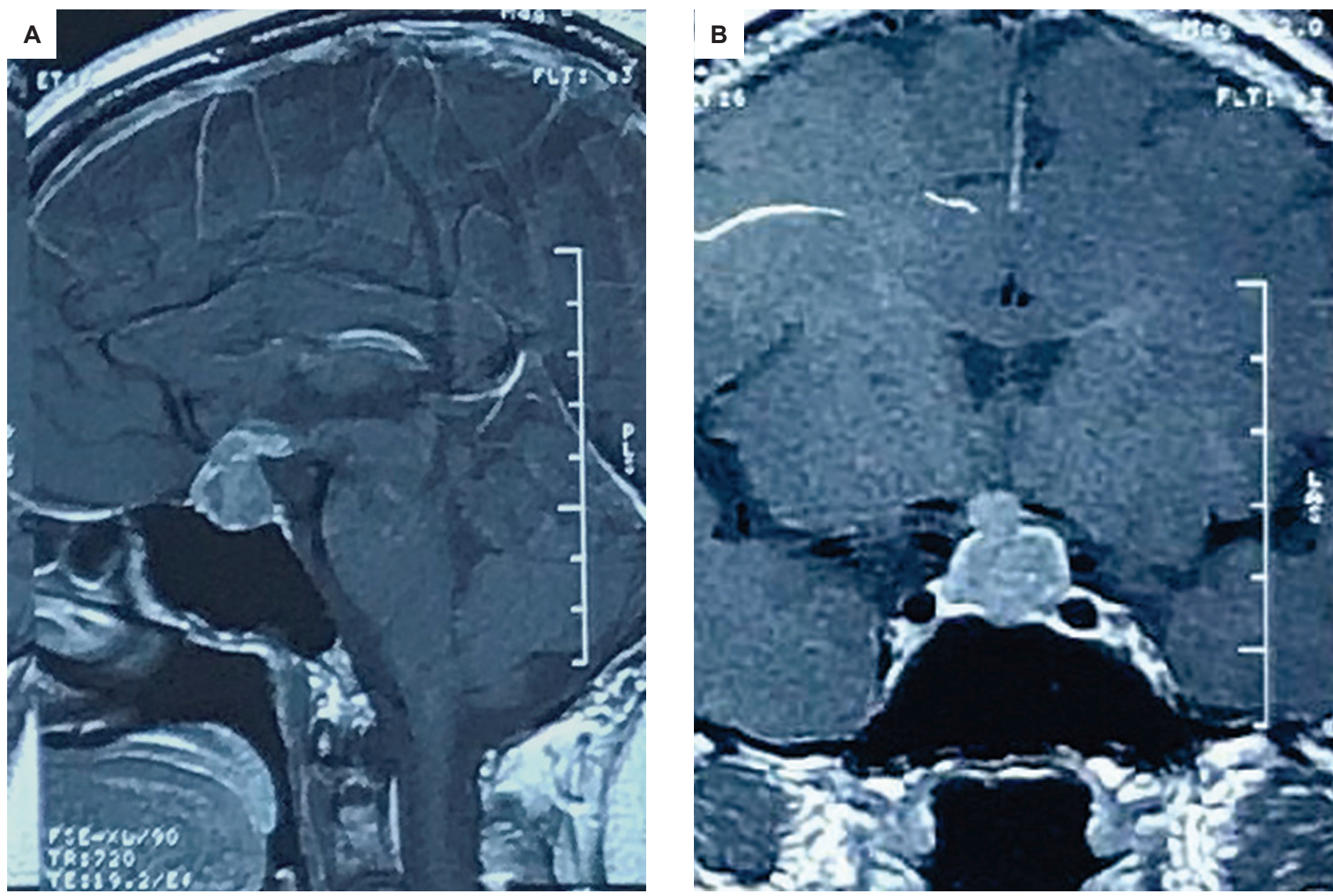

Figure 2. Magnetic resonance imaging of the pituitary showing lobulated heterogenous sellar mass with suprasellar extension and compression of optic chiasm, sagittal view in $\mathbf{A}$ and coronal view in $\mathbf{B}$.

compression of the optic chiasma (Figure 2). Initial laboratory tests showed normal blood count, Na: 144 $\mathrm{mmol} / \mathrm{L}$ (reference value [RV]:136-145), K: $4.1 \mathrm{mmol} / \mathrm{L}$ (RV: 3.5-4.4), and creatinine: 52 umol/L (RV: 44-80). Serum osmolality: $365 \mathrm{mOsm} / \mathrm{kg}$ (RV: 275-295) and urine osmolality: $66 \mathrm{mOsm} / \mathrm{kg}$ (RV: 300-900) taken during the polyuric phase were consistent with diabetes insipidus. Hormonal evaluation demonstrated insufficiencies of the corticotropic, thyroid and gonadotropic axis. (Table 1). She was started on hormonal replacement therapy (T. Hydrocortisone $10 \mathrm{mg} \mathrm{BD}$, L-Thyroxine $25 \mathrm{mcg}$ $\mathrm{OM}$ and T. Desmopressin $0.1 \mathrm{mg}$ BD).

Table 1. Initial hormonal evaluation

\begin{tabular}{lll}
\hline Hormone (unit) & Results & Reference Value \\
\hline LH (IU/L) & 0.1 & $2.4-12.6$ \\
FSH (IU/L) & 1.4 & $3.5-12.5$ \\
PRL (ug/L) & 6.73 & $4.79-23.30$ \\
IGF-1 (ug/L) & 93 & $103-310$ \\
ACTH (pmol/L) & $<1.1$ & $<10.2$ \\
Cortisol (nmol/L) & 43.6 & $171-536$ \\
FT4 (pmol/L) & 10.8 & $12-22$ \\
TSH (mIU/L) & 0.18 & $0.27-4.2$ \\
\hline
\end{tabular}

$\mathrm{LH}$ : luteinizing hormone, $\mathrm{FSH}$ : follicle-stimulating hormone, PRL: prolactin, IGF-1: insulin like growth factor -1, ACTH: adrenocorticotropic hormone, T4: thyroxine, TSH: thyroid stimulating hormone

The patient underwent endoscopic transsphenoidal pituitary surgery with resection of the mass. The postoperative recovery was uneventful and was discharged well with hormonal replacement therapy. She was seen in clinic one week postoperatively with the complaint of left shoulder pain. Left shoulder $\mathrm{x}$-ray showed pathological fracture of the left proximal humerus (Figure 3) and

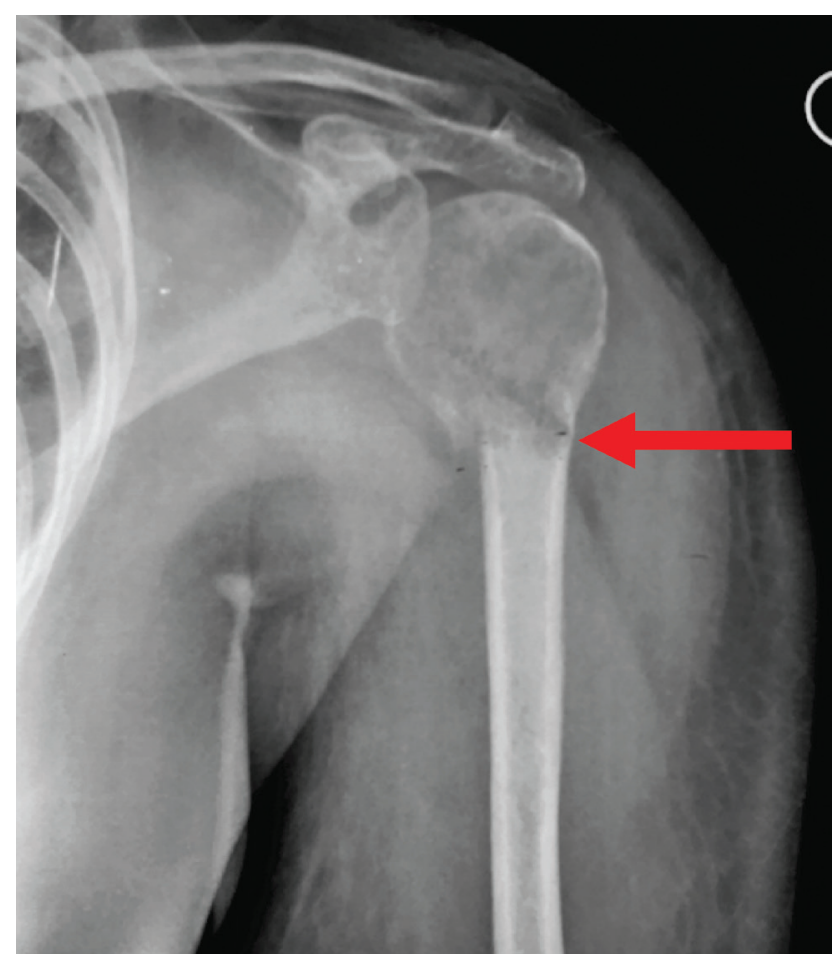

Figure 3. Pathological fracture of the left proximal humerus. 


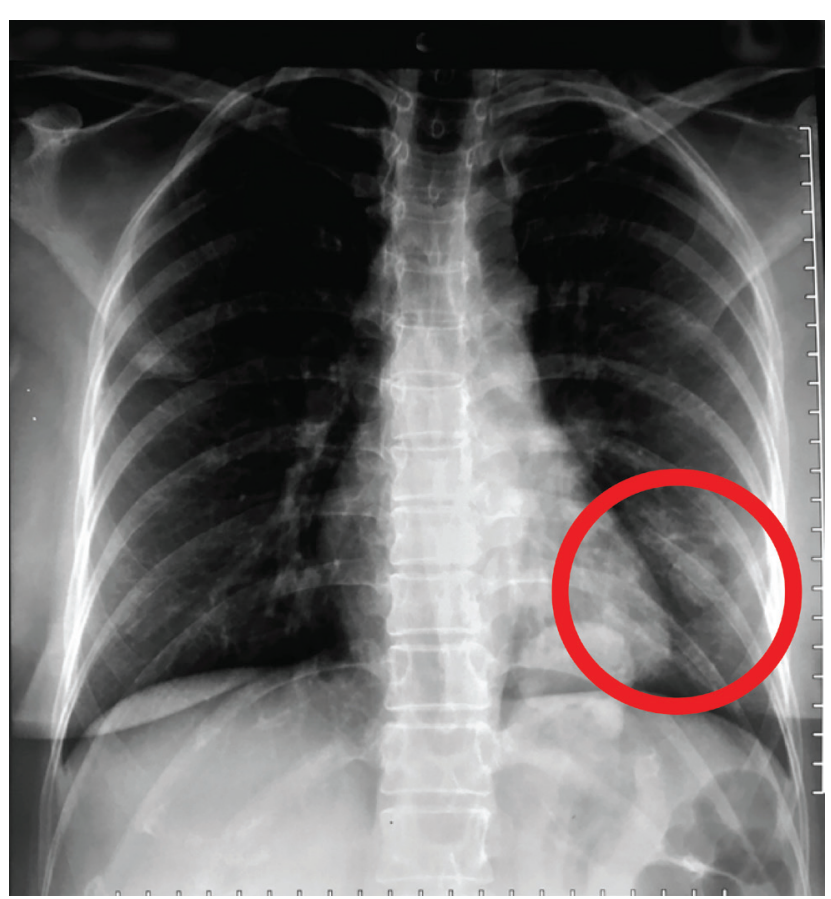

Figure 4. Suspicious left lung nodule.

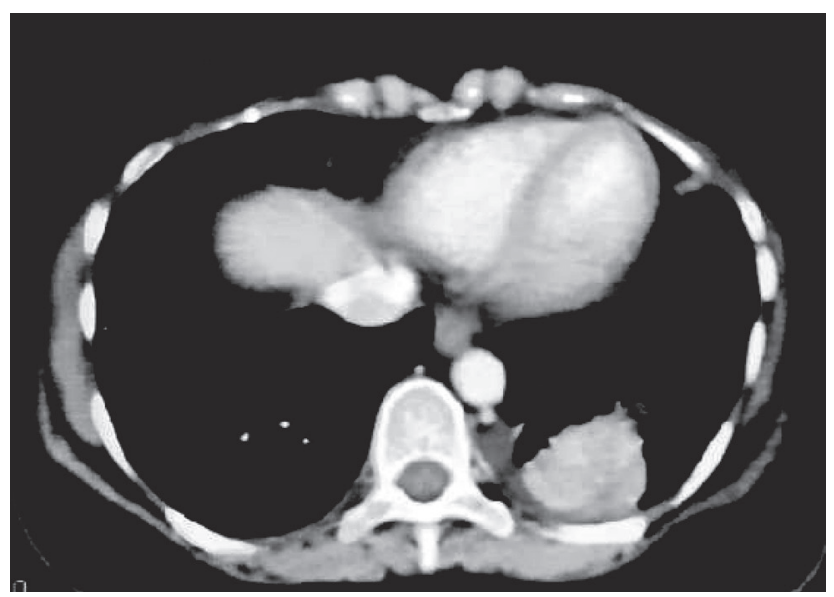

Figure 5. CT scan of the thorax revealed a mass $(3.3 \times 4.9$ $x 3.6 \mathrm{~cm}$ ) at the posterior basal segment of left lower lobe.

chest radiography (Figure 4) showed suspicious left lung nodule. A chest radiography was not done pre-operatively as there were no prior clinical indications. Pituitary histopathological analysis was later reported as metastatic adenocarcinoma. CT of the thorax, abdomen and pelvis revealed a mass $(3.3 \times 4.9 \times 3.6 \mathrm{~cm})$ at the posterior basal segment of left lower lobe (Figure 4) with multiple lung nodules of varying size noted bilaterally, enlarged mediastinal and hilar lymph nodes, and lytic lesion at proximal humerus and L5 vertebral body.

Subsequently, patient underwent CT guided biopsy of the left lung mass. The histopathological analysis was consistent with pulmonary adenocarcinoma and the immunohistochemistry results were positive for cytokeratin 7 (CK7) and thyroid transcription factor 1 (TTF1) and negative for CK20 and thyroglobulin. Patient underwent stereotactic radiation therapy to the pituitary mass and was started on oral chemotherapy gefitinib.

\section{DISCUSSION}

Pituitary adenoma is the most common cause of pituitary masses, constituting approximately $10 \%$ of all intracranial neoplasms. Pituitary gland metastasis accounts for only approximately $1 \%$ of all pituitary tumours in previous serial studies. ${ }^{5}$ Breast and lung tumours are the most common primary sites of malignant metastases to the pituitary gland, but other sites such as the gastrointestinal tract, prostate, kidney, thyroid, and pancreas have also been reported. ${ }^{6}$

Majority of the pituitary metastases are clinically silent and only $6.8 \%$ of cases are symptomatic. ${ }^{7}$ The most common presentations include diabetes insipidus (DI), visual field defects and hypopituitarism. DI is much more common in cases of pituitary metastases than in pituitary adenoma. Nearly $70 \%$ of symptomatic patients with pituitary metastases present with DI, whereas the rate of diabetes insipidus in patients with pituitary adenomas is less than $1 \% .^{8}$

Differentiating a pituitary metastasis from a pituitary adenoma is often difficult, as the clinical and radiologic findings are often nonspecific. ${ }^{9}$ Clinically, one helpful differentiating factor is the presence of DI, which is much more common in pituitary metastases than pituitary adenomas. The most characteristic imaging feature of a pituitary metastasis is enlargement or enhancement of the pituitary stalk with a pituitary mass. ${ }^{10}$

In our patient, she had pituitary metastases from lung adenocarcinoma and her initial presentation was visual field defect and diabetes insipidus. Her imaging showed typical snowman shape appearance of a pituitary adenoma. However, with no previous malignant history, clinical suspicion of pituitary metastases was low.

\section{CONCLUSION}

Pituitary metastases are rare but should be included in the differential diagnosis of invasive sellar lesions with pituitary stalk involvement, especially if it is associated with diabetes insipidus.

\section{Ethical Consideration}

Patient consent was obtained before submission of the manuscript.

Statement of Authorship

All authors certified fulfillment of ICMJE authorship criteria.

\section{Author Disclosure}

The authors declared no conflict of interest.

\section{Funding Source}

None.

\section{References}

1. Heaney AP. Clinical review: Pituitary carcinoma: Difficult diagnosis and treatment. J Clin Endocrinol Metab. 2011;96(12):3649-60. PMID: 21956419. PMCID: PMC3277423. https://doi.org/10.1210/jc.2011-2031.

2. Branch CL Jr, Laws ER Jr. Metastatic tumors of the sella turcica masquerading as primary pituitary tumors. J Clin Endocrinol Metab. 1987;65(3):469-74. PMID: 3624409. https://doi.org/10.1210/jcem-65-3469.

3. Morita A, Meyer FB, Laws ER Jr. Symptomatic pituitary metastases. J Neurosurg. 1998;89(1):69-73. PMID: 9647174. https://doi.org/10.3171/ jns.1998.89.1.0069 
4. Kontogeorgos G. Classification and pathology of pituitary tumors. Endocrine. 2005;28(1):27-35. PMID: 16311407. https://doi.org/10.1385/ ENDO:28:1:027.

5. Freda PU, Post KD. Differential diagnosis of sellar masses. Endocrinol Metab Clin North Am. 1999;28(1):81-117,vi. PMID: 10207686. https:// doi.org/10.1016/s0889-8529(05)70058-x.

6. Spinelli GP, Lo Russo G, Miele E, et al. Breast cancer metastatic to the pituitary gland: A case report. World J Surg Oncol. 2012;10:137. PMID: 22776141. PMCID: PMC3443051. https://doi.org/10.1186/14777819-10-13

7. Teears RJ, Silverman EM. Clinicopathologic review of 88 cases of carcinoma metastatic to the pituitary gland. Cancer. 1975;36(1):216-20. PMID: 1203849. https://doi.org/10.1002/10970142(197507)36:1<216::aid-cncr2820360123>3.0.co;2-e.
8. Reddy P, Kalemkerian GP. Unusual Presentations of Lung Cancer: Case 1. Diabetes insipidus as the initial manifestation of non-small lung cancer. J Clin Oncol. 2002;20(23):4597-4602. PMID: 12454118. https://doi.org/10.1200/JCO.2002.20.23.4597.

9. Fassett DR, Couldwell WT. Metastases to the pituitary gland. Neurosurg Focus. 2004;16(4); E8. PMID: 15191337.

10. Morita A, Meyer FB, Laws ER Jr. Symptomatic pituitary metastases. J Neurosurg. 1998;89(1):69-73. PMID: 9647174. https://doi.org/10.3171/ jns.1998.89.1.0069.

Authors are required to accomplish, sign and submit scanned copies of the JAFES Author Form consisting of: (1) Authorship Certification, that authors contributed substantially to the work, that the manuscript has been read and approved by all authors, and that the requirements for authorship have been met by each author; (2) the Author Declaration, that the article represents original material that is not being considered for publication or has not been published or accepted for publication elsewhere, that the article does not infringe or violate any copyrights or intellectual property rights, and that no references have been made to predatory/ suspected predatory journals; (3) the Author Contribution Disclosure, which lists the specific contributions of authors; and (4) the Author Publishing Agreement which retains author copyright, grants publishing and distribution rights to JAFES, and allows JAFES to apply and enforce an Attribution-Non-Commercial Creative Commons user license. Authors are also required to accomplish, sign, and submit the signed ICMJE form for Disclosure of Potential Conflicts of Interest. For original articles, authors are required to submit a scanned copy of the Ethics Review Approval of their research as well as registration in trial registries as appropriate. For manuscripts reporting data from studies involving animals, authors are required to submit a scanned copy of the Institutional Animal Care and Use Committee approval. For Case Reports or Series, and Images in Endocrinology, consent forms, are required for the publication of information about patients; otherwise, appropriate ethical clearance has been obtained from the institutional review board. Articles and any other material published in the JAFES represent the work of the author(s) and should not be construed to reflect the opinions of the Editors or the Publisher.

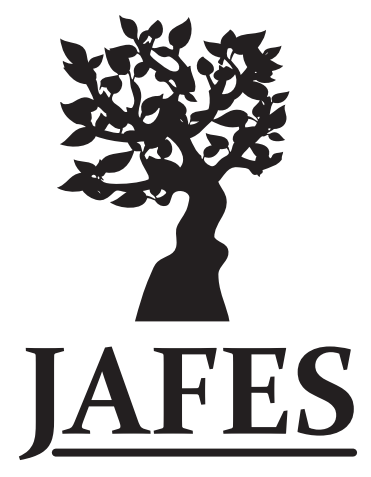

\section{Send your paper to the publication pathway. Instructions to Authors at www.ASEAN-endocrinejournal.org.}

